\title{
Study of the Resonance Diffraction Phenomena on Gratings by the Rigorous Coupled Wave Method with Modified Equation System
}

\author{
V. Fitio ${ }^{1}$, I. Yaremchuk ${ }^{1, *}$, A. Bendziak ${ }^{1}$, Y. Bobitski1,2 \\ ${ }^{1}$ Lviv Polytechnic National University, 12, S. Bandera St., 79013 Lviv, Ukraine \\ 2 University of Rzeszow, 16b, T. Rejtana St., 35959 Rzeszow, Poland
}

(Received 05 May 2020; revised manuscript received 15 October 2020; published online 25 October 2020)

\begin{abstract}
Results of a numerical analysis of the diffraction of optical waves of transverse magnetic (TM) polarization on gratings under the electromagnetic field resonance conditions are presented. Rigorous coupled wave analysis (RCWA) with modified equation system has been used. Modification is in change of the Toeplitz matrices in differential equation systems. These matrices are formed by complex Fourier series of a periodic function of the dielectric permittivity and its inversed function. Rectangular function of the dielectric permittivity per one period is changed by trapezoidal function; however, grating relief remains rectangular. Such replacement of the dielectric permittivity function more precisely corresponds to actual gratings. Oscillations of the reflectance and transmittance depending on the number of used coupled waves were reduced using modified equation system. Moreover, there is better convergence, especially in case of metallic gratings on the dielectric substrates, in which the localized plasmon resonance or the electromagnetic field resonance can occur in the grating slit. Any changes of the convergence with the use of modified systems of equations are not present in the case of dielectric gratings on the metallic substrates in comparison to the traditional expansion of the dielectric constant into a Fourier series. Surface plasmon-polariton resonance of a metal grating on metal substrate in case of which the reflectance from the grating is equal to zero was researched. There is a particularly complicated dependence of the reflectance on the number of coupled waves used in the analysis for both modifications of the equation system. Strong oscillations of the reflection coefficient from the grating are observed at certain values of coupled waves, which decrease with their growth.
\end{abstract}

Keywords: Rigorous coupled wave analysis, Localized plasmon resonance, Diffraction gratings.

DOI: 10.21272/jnep.12(5).05007

PACS numbers: 42.25.Bs, 42.79.Dj

\section{INTRODUCTION}

Rigorous coupled wave analysis (RCWA) is widely used for studying the diffraction of electromagnetic waves by gratings and its accuracy increases when the number of used coupled waves increases [1]. There is the fast convergence of RCWA for all types of gratings. This is explained by the jump of dielectric permittivity in the grating at the metal/dielectric interface along the axis of periodicity. It causes the jump of a component of the electric field strength which is oriented along the $x$ axis [2]. However, the convergence of the method is very slow at studying diffraction of TM polarized waves by rectangular metal gratings in the case of the electromagnetic field resonance, for example, plasmon or surface plasmon-polariton resonances, which require to use a large number of coupled waves [3]. It is explained by a jump of the tangential component of the electric field strength at the border media with different dielectric permittivities. The increase in the number of coupled waves in calculations of RCWA twice leads to the increase in computing time eight times [4]. It can be explained by the fact that there are much more matrix operations which are used to solve the linear system of differential equations.

A number of optical effects associated with resonance phenomena appear in the periodic metal-based structure. As an example, the total absorption can occur due to the waveguide modes resonance or surface plasmon-polariton resonance in the grating in case of the dielectric grating on the metal substrate [2]. Plasmon-polariton resonance can occur in the metal grating on the metal substrate. Extraordinary optical transmittance can be achieved due to the resonance of the field in the grating slit for both TM [5] and TE [6] polarizations in case of using a thick metal grating on the dielectric substrate. Transmittance slightly less than one is observed in the multilayer structure of type dielectric grating/thin metal film/dielectric grating/dielectric substrate, as a result of the waveguide modes resonance in the gratings [7]. Reflectance can be obtained equal to one in a narrow spectral band due to waveguide resonance in the dielectric grating with a sinusoidal relief on the dielectric substrate [8].

RCWA is used to study all these resonant phenomena. However, it should be noted that it is necessary to use a large number of coupled waves for the analysis of the structures consisting of metal elements, especially when different resonances occur for TM polarized waves. In [9], it is shown that it is necessary to use 150-200 coupled waves for accurate analysis of the metal grating with the narrow slits. Electromagnetic fields with an amplitude much larger than the amplitude of the incident wave can appear in the grating if the resonance band is narrow. Resonance is disturbed with the small change in the structure parameters, which is used in measuring instruments [10]. In the case of dozens of times field enhanced in the grating under resonance more than 200 coupled waves must be used for accurate analysis [3].

In [11], the criteria of convergence of numerical simulation of metal-dielectric grating are presented and grounded. However, this work represents results

\footnotetext{
*iryna.y.yaremchuk@lpnu.ua
} 
for metal-dielectric grating where the dielectric permittivity of the metal is purely negative. It means that there are no Joule losses in the grating. Therefore, additional research with the ability to improve RCWA is necessary for its successful use to calculate the diffraction by rectangular gratings at the significant field enhancement, especially at TM polarization.

In our studies, we chose silver as a metal. The resonance phenomena in the silver gratings are most pronounced, and the largest fields appear at resonances. Thus, we set ourselves two aims: can the proposed modification of the expansion of the dielectric permittivity periodic function in the Fourier series in accordance with equation (2) improve the convergence of the calculations? How effective is the use of RCWA (if one considers that there is a corresponding commercial software) to research the diffraction by grating on base of metal elements, in particular silver elements, under resonance conditions?

\section{NUMERICAL TECHNIQUE}

Toeplitz matrices are formed on base of complex Fourier coefficients of dielectric permittivity [1]. These matrices consist of terms of the numerical series with numbers from $(-N+1) / 2$ to $(N-1) / 2$, where $N$ is odd, if $N$ coupled waves are used in the system of differential equations for RCWA. In fact, the dielectric permittivity is represented in RCWA inaccurately due to the truncation of the complex Fourier series of the periodic function of the grating dielectric permittivity. Especially this inaccuracy will be noticeable for the rectangular grating (a discontinuity of the first kind in the functional dependence of the dielectric permittivity of the grating on the coordinate $x$ ). It is necessary to increase the number of terms of the Fourier series for a better representation of the functional dependence of the dielectric permittivity. However, such an increase in the number of the series terms according to the dimension of the Toeplitz matrices results in the increase in RCWA calculation time.

Firstly, the RCWA for TM polarized waves should be described on base of works $[12,13]$, where the tangential components of the electric and magnetic fields of the electromagnetic wave in the grating are connected by the system of differential equations as follows:

$$
\begin{gathered}
\frac{d E_{j}(z)}{d z}=-i k H_{j}(z)+i \frac{k_{j, x}}{k} \sum_{p}\|\varepsilon\|_{j-p}^{-1}(z) k_{p, x} H_{p}(z), \\
\frac{d H_{j}(z)}{d z}=-i k \sum_{p}\left\|\frac{1}{\varepsilon}\right\|_{j-p}^{-1}(z) E_{p}(z),
\end{gathered}
$$

where $k=\frac{2 \pi}{\lambda}, x$ is the component of vector $k_{j, x}$ connected with the wave number $k_{0, x}$ by expressions $k_{j, x}=k_{0, x}-j \frac{2 \pi}{\Lambda}, k_{0, x}=\frac{2 \pi \sqrt{\varepsilon_{1}}}{\lambda} \sin \theta_{1,0}, \theta_{1,0} \quad$ is the angle of incidence of the plane wave on the grating, $\|\varepsilon\|_{j-p}^{-1}$, $\left\|\frac{1}{\varepsilon}\right\|_{j-p}^{-1}$ are inverse Toeplitz matrices which are formed on base of expansion $\varepsilon(x, z)$ and $1 / \varepsilon(x, z)$ in the complex Fourier series.

The system of differential equations with the firstorder derivatives can be reduced to a system of equations in the matrix form with the second-order derivatives as follows:

$$
\frac{d^{2} \mathbf{H}}{d z^{2}}=\mathbf{B}_{m} \mathbf{H}
$$

The matrix $\mathbf{B}_{m}$ will be square with $N \times N$ matrix elements if $N$ coupled waves will be used and the $\mathbf{H}$ vector will consist of $N$ components $H_{j}(z)$. The dependences of the dielectric permittivity of the rectangular grating and its representation in the form of a finite complex Fourier series with $N$ terms in two modifications are presented in Fig. 1.

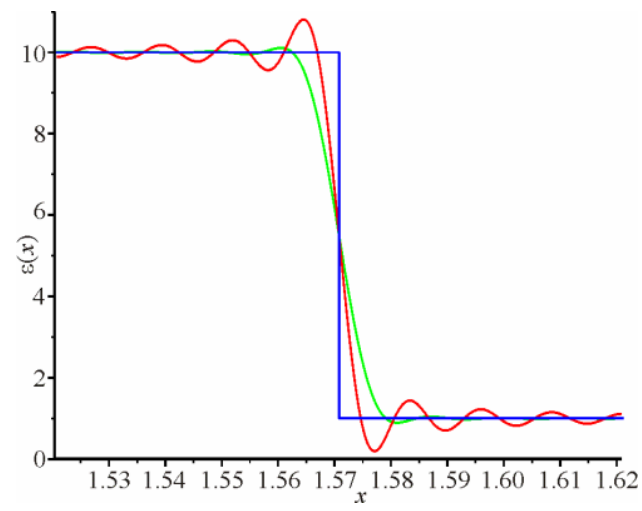

Fig. 1-Representation of the functional dependence of the dielectric permittivity of a part of the rectangular grating; its presentation in the form of the traditional Fourier series (red) and in the form of the modified Fourier series (green) with the following parameters: $\Lambda=2 \pi, F=0.5, N=501, \varepsilon_{21}=1.0, \varepsilon_{22}=10$; $x$ varies in the range $[\pi / 4-0.05, \pi / 4+0.05]$

The representation of the dielectric permittivity in the form of the finite Fourier series (red) differs from real dielectric permittivity (blue) as follows: the rectangle deformed into the trapezoid, two levels of dielectric permittivity 1 and 10 are modulated by oscillations. Trapezoid more corresponds to reality, since dielectric permittivity on the surface of a solid does not change by a jump, but smoothly due to the absorption of the air components by the metallic surface. On the other hand, oscillations can result in error analysis since oscillations in the dielectric permittivity form a high-frequency grating. It can lead to unwanted and non-existent resonant interaction between certain coupled waves.

Terms of the traditional Fourier series of the dielectric permittivity $\varepsilon(x)$ for the rectangular grating can be expressed as follows:

$$
c_{n}=\left\{\begin{array}{cl}
\varepsilon_{21}(1-F)+\varepsilon_{22} F, & \text { if } n=0 \\
\left(\varepsilon_{22}-\varepsilon_{21}\right) \frac{\sin (\pi n F)}{\pi n}, & \text { if } n \neq 0
\end{array}\right.
$$

In the same way, the Fourier coefficients series is calculated for the dependence $1 / \varepsilon(x)$. The Toeplitz matrix is also formed on their base in RCWA. 
Dielectric permittivity can be represented in the form of the trapezoid with an insignificant level of oscillations. Such dependence can be written in the form of the finite Fourier series whose terms are expressed as follows:

$$
c_{n}=\left\{\begin{array}{c}
\varepsilon_{21}(1-F)+\varepsilon_{22} F, \quad \text { if } n=0 \\
\left(\varepsilon_{22}-\varepsilon_{21}\right) \frac{\sin (\pi n F) \sin [\pi n /(N-1)](N-1)}{(\pi n)^{2}}, \text { if } n \neq 0
\end{array}\right.
$$

where $N$ is the number of coupled waves used in the diffraction analysis.

The dependence of the dielectric permittivity of the grating in the form of the complex Fourier series (green) with $N$ terms according to equation (2) is shown in Fig. 1. There are practically no oscillations; the functional dependence of the dielectric permittivity is represented by a shape close to the trapezoid. However, the lateral sides are deviated from the vertical in comparison to the curve shown in red in Fig. 1. Both curves (green and red) go to the rectangular dependence with the growth of $N$ to infinity. But oscillations on the red curve do not disappear and their amplitude does not decrease, and the frequency of oscillations increases.

The integral estimate of the proximity of the dielectric permittivity $\varepsilon(x, N)$ represented by the series to the real dielectric permittivity $\varepsilon(x)$ can be determined by the following expression:

$$
\|\varepsilon(x)-\varepsilon(x, N)\|=\frac{1}{\Lambda} \int_{-\frac{\Lambda}{2}}^{+\frac{\Lambda}{2}}|\varepsilon(x)-\varepsilon(x, N)| d x .
$$

Binary logarithm of the norm of the difference depending on $N$, in accordance with equation (3) between the functional dependence of the dielectric permittivities represented by the series in accordance with (1) and (2) and the real dielectric permittivity $\varepsilon(x)$ are presented in Fig. 2. The binary logarithms of the norm decrease when $N$ increases for both cases. The decrease is very fast when $N$ is changed from 21 to 100 , and much slower under the change of $N$ from 150 to 501 . This allows us to conclude that there will be chaotic changes in the results of calculations when $N$ will change from 20 to 100 . For example, transmittance of the metallic grating can be significantly changed even when $N$ is changed on one. The results of calculations slowly tend to their stationary value after $N>150$, but some oscillations are possible [14].

The number of required coupled waves can be more than 500 for the required accuracy [2]. It also can be expected the significant enhancement of the field in the narrow spatial region in the grating at the metal/dielectric interface. For example, it is in the metal nanowires periodically arranged on the dielectric substrate under plasmon resonance. Plasmon resonance in nanoparticles of the noble metals is quite broadband [15]. Fig. 2 shows that difference $\|\varepsilon(x, N)-\varepsilon(x)\|$ of the dielectric permittivity of the rectangular grating and grating whose coefficients are expressed by equation (2) is much smaller in comparison with $\|\varepsilon(x, N)-\varepsilon(x)\|$ bet-

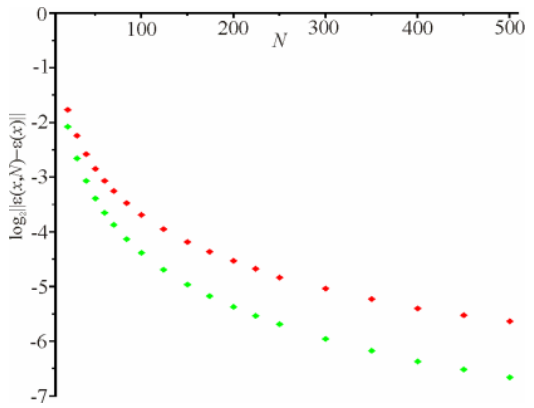

Fig. 2 - Binary logarithm of the norm of the difference of dielectric permittivities on $N$ : $\Lambda=2 \pi, F=0.5, \varepsilon_{21}=1.0, \varepsilon_{22}=10$. Terms of the series calculated by equation (1) are represented in red; terms of series calculated by the equation (2) are represented in green

ween the rectangular grating and grating, whose expansion coefficients are calculated by equation (1). It should be noted that the dependence of the binary logarithm of the norm difference on $N$ according to equation (2) decreases more sharply than the corresponding dependence, where the norm difference is calculated by equation (1). Therefore, it can be assumed that the use of the Toeplitz matrix based on equation (2) in RCWA improves the accuracy of the calculations and gives better convergence which will be shown in the next part.

\section{RESULTS AND DISCUSSION}

The analysis of the grating with the following parameters: $\varepsilon_{1}=\varepsilon_{21}=1.0, \varepsilon_{3}=2.25, \varepsilon_{22}$ is the dielectric permittivity of silver in accordance with [17] at the wavelength of $0.4 \mu \mathrm{m}, \Lambda=0.1 \mu \mathrm{m}, F=0.5, d=0.05 \mu \mathrm{m}$, was carried out. The structure represents the squaresection nanowires periodically arranged on the dielectric substrate. There are only reflected and transmitted waves in the far zone whose intensities are denoted by the $T$ and $R$. There is absorption in the metallic gratings which is calculated by the equation $A=1-R-T$. Dependences of the reflection $(R)$, transmission $(T)$ and absorption $(A)$ coefficients of a such periodic structure on the number of used coupled waves are presented in Fig. 3. The oscillations are significantly less in the transmission and absorption dependences on the number of coupled waves if the terms of the Fourier series are calculated by equation (2), as opposed to when the terms of the Fourier series are calculated by equation (1). The oscillations in the reflection spectrum are practically absent if the terms of the Fourier series are calculated by equation (2). The analysis of numerical calculation data showed that the difference in the absorption for the red curve for $N=205$ and $N=207$ is 0.0369 for the metal grating on the dielectric substrate at $F=0.5$. This difference increases when $N$ increases and reaches a value of 0.0407 for $N=333$ and $N=335$. There is an increase in oscillations with the growth of $N$. Consequently, there is a slow divergence. The oscillation decreases from 0.0188 at $N=205$ and $N=207$ to 0.0175 at $N=333$ and $N=335$ when the coefficients of the Fourier series are represented in accordance with equation (2). Notably, here the oscillations decrease with the growth of $N$. Thus, a slow, but certain convergence of the calculation results is manifested; there is a significant absorption of more than 0.6 due to the reso- 
nance of surface localized plasmons in nanowires. It can be explained by the appearance of significant fields in the periodic nanostructure.

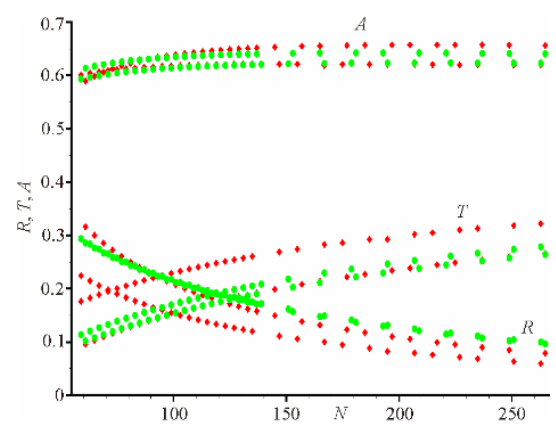

Fig. 3 - Dependence of the reflection $(R)$, transmission $(T)$ and absorption $(A)$ coefficients on the number of coupled waves

The maximum amplitude of the tangential component of the electric field reaches more than 110 relative units in the narrow spatial region at the metal/dielectric interface. It is typical for plasmon resonance. It should also be noted that the maximum electric field strength per the period is negligibly smaller when equation (2) is used in comparison to the fields obtained by equation (1) calculating $c_{n}$.

Fig. 4 shows the dependence of the reflection $(R)$, transmission $(T)$ and absorption $(A)$ of periodic structure with the following parameters: $\varepsilon_{1}=\varepsilon_{21}=1.0$, $\varepsilon 3=2.25$, where $\varepsilon_{22}$ is the dielectric constant of silver at the wavelength of $0.4 \mu \mathrm{m}, \quad \Lambda=0.25 \mu \mathrm{m}, \quad F=0.2$, $d=0.05 \mu \mathrm{m}, \lambda=0.4 \mu \mathrm{m}$. Therefore, the oscillations are significantly less in the reflection, transmission and absorption dependences on the number of coupled waves if the terms of the Fourier series are calculated by equation (2) in comparison with the case when the terms of the Fourier series are calculated according to equation (1).

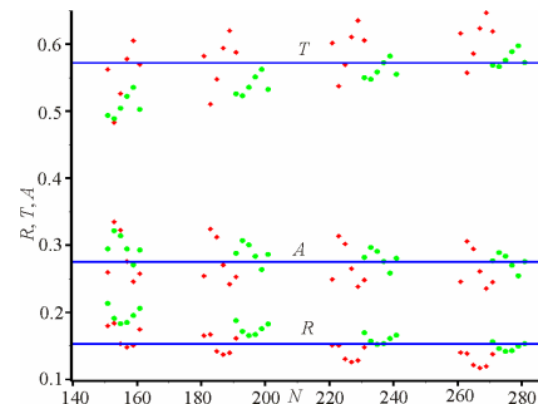

Fig. 4 - Dependence of the reflection $(R)$, transmission $(T)$ and absorption $(A)$ on the number of coupled waves. Blue lines (horizontal straight lines) correspond to the values of reflection, transmission and absorption coefficients at $N=281$, if the coefficients of the Fourier series were calculated by equation (2)

The green dots are more compactly located near the blue lines compared with the arrangement of the red dots near these lines. In addition, the distribution of the green points with increasing $N$ decreases faster than the distribution of the red dots. Thereby, there is better convergence, when the coefficients of the Fourier series are determined by equation (2). The maximum value of the electric field strength module is close to 60 relative units when 281 coupled waves are used.

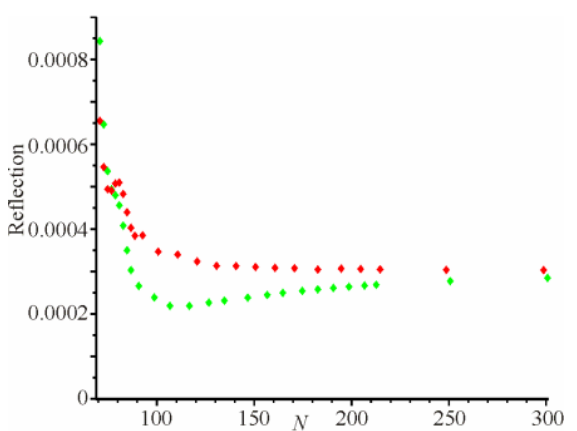

Fig. 5-The dependence of the reflection on the number of coupled waves of the dielectric grating in which the resonance of surface plasmon-polaritons is excited

In the next step, the periodic structures consisting of the dielectric or metal grating on the silver substrate were researched. The resonance of surface plasmonpolariton waves can be excited in this structure under certain grating parameters, which results in a zero reflection coefficient [2]. Let us first consider the simpler case, the dielectric grating on the metal substrate with the following parameters: $\varepsilon_{1}=\varepsilon_{21}=1.0, \varepsilon_{3}=-52.75+$ $+i \cdot 1.1544 \quad$ (silver), $\quad \varepsilon_{22}=9.0, \quad \Lambda=1.0 \mu \mathrm{m}, \quad F=0.143$, $d=0.055 \mu \mathrm{m}, \lambda=1.0251 \mu \mathrm{m}$. The two surface plasmonpolariton waves are excited at the surface of the metal under normal incidence of a plane wave on such a structure at the given parameters. These waves move toward each other. Here, reflection coefficient is less than 0.0003. Obviously, reflection coefficient equal to zero can be obtained when parameters of the periodic structure are carefully selected. Fig. 5 shows the coefficient of reflection depending on the number of used coupled waves of such a periodic structure.

There are rapid changes in the coefficient of reflection when the number of coupled waves is changed to 100 and a slow change at the number of coupled waves more than 200. In this case, there is no visible advantage of the method of calculating the coefficients of the expansion of the dielectric constant in the Fourier series for equations (1) or (2). This result, apparently, relates to the fact that the excitation of the resonance in the periodic structure is due to the dielectric gratings.

Considering Fig. 5, it can be noted that for this periodic structure, both curves represent the reflection of the dielectric grating on the metal under the plasmonpolariton resonance, have practically the same values of 0.00026 for the green curve at $N=213$ and 0.000304 for the red curve at $N=215$, and the difference between the reflection coefficients is 0.00004 . However, we can see some oscillations at $N<120$, if the elements of the Toeplitz matrix are calculated by equation (1).

The dependence of the reflection coefficient on the number of coupled waves has a rather unexpected character for the periodic structure, in which the excitation of the surface plasmon-polariton resonance is due to the metal grating on the metal substrate. It is possible to obtain a practically zero reflection coefficient at resonance with the following gratings parameters: $\varepsilon_{1}=\varepsilon_{21}=1.0$, $\varepsilon_{22}=\varepsilon_{3}=-51.18+i \cdot 1.1176$ (silver), $\Lambda=1.0 \mu \mathrm{m}, \quad F=0.5$, $d=0.0133 \mu \mathrm{m}, \lambda=1.01089 \mu \mathrm{m}$. The reflection coefficients depending on the number of coupled waves of such a periodic structure are shown in Fig. 6. 


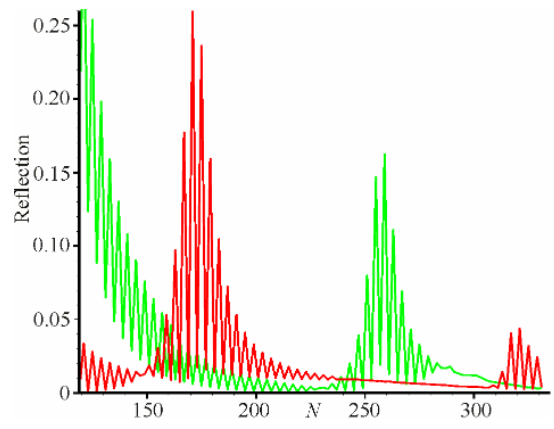

Fig. 6 - The dependence of the reflection on the number of coupled waves of the metal grating in which the resonance of the surface plasmon-polaritons is excited

In the case of excitation of the surface plasmonpolariton wave by the metal grating, the reflection coefficient does not have a smooth dependence on the number of coupled waves, similar to the dependences in Fig. 5. Some features may be noted here. One of them is that in some ranges of change of $N$ by two units the coefficient of reflection varies significantly, and this value decreases with the growth of $N$. The second feature is that there are variations in the range of $N$ in which the jumps in the reflection coefficient are insignificant and at some intervals of change in $N$ they are practically absent. These intervals increase when $N$ increases. It can be expected that oscillations of the reflection coefficient will go to zero with increasing $N$. The reflection coefficient will have a small value for the parameters of the periodic structure described above. The reflection coefficient is less than 0.003 for the "green" dependence at $N=331$. The maximum electric field strength arises when $z=0$, that is at the grating/air interface and is equal a little more than 60 relative units. The maximum value of the magnetic component of the electromagnetic wave reaches 35 relative units at $z=0$. This unrepresentative dependence of the reflection coefficient on the number of coupled waves of the metal grating on the metal substrate can be explained by the peculiarities of the square root of the eigenvalues $\mu_{n}$ of the matrix $\mathbf{B}_{m}$ where $n$ varies from 1 to $N$. Among $N$ eigenvalues there are four $\sqrt{\mu}$ which have large imaginary parts and small real parts. The comparison of the set of two eigenvalues at $N=201$ and $N=331$ shows that the change in $N$ practically does not change, and the other three $\sqrt{\mu_{j \neq 1}}$ essentially change even when $N$ is changed by two units. These $\sqrt{\mu_{j \neq 1}}$ can result in the "false resonance" in the dielectric part of the grating, which is bounded by metal walls, that is the resonance in the grating slit. This "false resonance" disturbs the surface plasmon-polariton resonance and reflection coefficient becomes non-zero. Fig. 6 shows that oscillations of the reflection coefficient decrease when $N$ increases. This can be explained by the fact that the real part $\sqrt{\mu_{j \neq 1}}$ (responsible for absorption) increases when $N$ increases. It results in the decrease of the "false resonance," and one can assume that with large $N$ "false resonance" will disappear. It should also be noted that the thickness of the grating $d=0.01337 \mu \mathrm{m}$ and the wavelength $\lambda=1.01089 \mu \mathrm{m}$ at which the reflection coefficient is practically zero $(<0.001)$ are found at $N=123$, as the "blue" curve demonstrates in Fig. 6. When $N$ is changed by two units, the reflection coefficient increases sharply. The conditions of appearance of the plasmonpolariton resonance found at $N=123$ provide the resonance in general, that is with a large $N$.

\section{CONCLUSIONS}

The results of RCWA studies of the diffraction of TM polarized waves by rectangular gratings depending on the number of coupled waves $(N)$ have shown a complicated character for both representations of the periodic functional dependence of the dielectric permittivity of the grating. In the first method, the traditional representation of the grating permittivity is used in the form of the rectangular periodic function which has discontinuity of the first kind. In the second method, the dielectric permittivity is continuous in the form of the trapezoidal functional dependence. In case of the periodic structure on base of the metal grating on the dielectric substrate, there is a significant decrease in the oscillations of the transmission, reflection and absorption coefficients at the new representation of the dielectric permittivity in the Fourier series. Moreover, these oscillations decrease when $N$ increases. The absorption oscillations are significantly larger and slowly increase when $N$ increases for the traditional representation of the dielectric permittivity in the Fourier series. Thus, the application of the expansion function of the dielectric permittivity in RCWA in the Fourier series with coefficients in accordance with equation (2) improved the convergence of the calculation and significantly reduced oscillations. However, the convergence of the calculation results is still small, which agrees with Fig. 2, where the norm of difference slowly tends to zero with increasing $N$ in both representations of the dielectric permittivity of the grating. It is possible to predict the results of diffraction at $N \rightarrow \infty$ by developing the appropriate interpolation methods.

\section{ACKNOWLEDGEMENTS}

This research was funded by the Ministry of Education and Science of Ukraine (DB/MEV No 0118U000267).

\section{REFERENCES}

1. M.G. Moharam, T.K. Gaylord, E.B. Grann, T.K. Gaylord, J. Opt. Soc. Am. A; 12, 1068 (1995).

2. V.M. Fitio, Y.V. Bobitski, J. Opt. A: Pure Appl. Opt. 6, 943 (2004).

3. M. Weismann, D.F. Gallagher, N.C. Panoiu, J. Opt. 17, 125612 (2015).

4. L. Li, J. Opt. Soc. Am. A. 13, 1024 (1996).

5. J.M. Steele, C.E. Moran, A. Lee, C.M. Aguirre, and N.J. Halas, Phys. Rev. B. 68, 205103 (2003).

6. E. Moreno, L. Martín-Moreno, F.J. García-Vidal, J. Opt. A: Pure Appl. Optics 8, S94 (2006).

7. V.M. Fitio, Y.V. Bobitski, 7th International Conference on 
Laser and Fiber-Optical Networks Modeling (LFNM-2005), 163 (Yalta: Crimea: 2005).

8. I. Yaremchuk, T. Tamulevičius, V. Fitio, I. Gražulevičiūte, Y. Bobitski, S. Tamulevičius, Opt. Commun. 301, 1 (2013).

9. M.M.J. Treacy, Phys. Rev. B. 66, 195105 (2002).

10. K.H. Yoon, M.L. Shuler, S.J. Kim, Opt. Express. 14, 4842 (2006).

11. L. Li, G. Granet, J. Opt. Soc. Am. A 28, 738 (2011)

12. L. Li, J. Opt. Soc. Am. A 13, 1024 (1996).
13. E. Popov, M. Navière, N. Bonod, J. Opt. Soc. Am. A 21, 46 (2004).

14. V.M. Fitio, I.Y. Yaremchuk, Y.W. Bobitski, Telecomm. Radio Eng. 72, 661 (2013).

15. S.K. Ghosh, T. Pal, Chem. Rev. 107, 4797 (2007).

16. P.S.J. Russell, J. Opt. Soc. Am. A 1, 293 (1984).

17. V. Fitio, I. Yaremchuk, O. Vernyhor, Ya. Bobitski, Appl. Nanosci. 8, 1015 (2018).

\title{
Вивчення резонансних дифракційних явищ на гратках точним методом зв'язаних хвиль $з$ модифікованою системою рівнянь
}

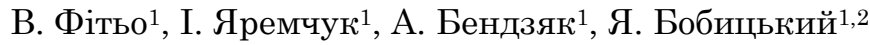 \\ ${ }^{1}$ Національний університет «Львівська політехніка», вул. С. Бандери 12, 79013 Львів, Україна \\ 2 Університет Ржешува, вул. Т. Рейтана 16b, 35959 Ржешув, Польща
}

\begin{abstract}
В роботі представлені результати числового аналізу дифракції оптичних хвиль поперечної магнітної (ТМ) поляризації на гратках при наявності резонансу електромагнітного поля. Використано RCWA, в якому модифікована система рівнянь. Модифікація полягае в тому, що у системі диференціальних рівнянь змінені матриці Теплиця, які формуються на основі комплексних рядів Фур’е періодичної функції діелектричної проникності гратки та оберненої їй функції. Прямокутна функція зміни діелектричної проникності на періоді замінена на функцію трапеції, проте рельеф гратки лишається прямокутним. Така заміна функції діелектричної проникності точніше відповідає реальним граткам. Виявлено зменшення осциляцій коефіціентів відбивання та пропускання в залежності від кількості використаних зв'язаних хвиль та кращу збіжність результатів розрахунку для видозміненої системи рівнянь, особливо для металевих ґраток на діелектричних підкладках, в яких може спостерігатися резонанс локалізованих плазмонів, або резонанс електромагнітного поля в щілині гратки. Показано, що для діелектричних ғраток, розташованих на металевій підкладщі, немае ні покращення ні погіршення збіжності при використанні модифікованої системи рівнянь в порівнянні з традиційним розкладом діелектричної проникності в ряд Фур'е. Для структури металева гратка на металевій підкладщі досліджувався резонанс поверхневих плазмон-поляритонів, при виникненні якого коефіціент відбивання від гратки рівний нулю. Тут виникає особливо складна залежність коефіщієнта відбивання від кількості використаних зв'язаних хвиль при аналізі для обох модифікацій систем рівнянь. Спостерігаються сильні осциляції коефіціента відбивання від гратки при певних значеннях зв'язаних хвиль, які з їх ростом зменшуються.
\end{abstract}

Ключові слова: Точний аналіз зв'язаних хвиль, Локалізований плазмонний резонанс, Дифракційна гратка. 